\title{
BLOOD TRANSFUSION REQUIREMENTS IN THE ELDERLY WITH FRACTURED NECK OF FEMUR: A NEW PROTOCOL
}

\author{
A Sinha, Associate Specialist, Department of Orthopaedics; \\ DW Gorst, Consultant Haematologist, Lancaster Acute Trust
}

\section{INTRODUCTION}

Most elderly patients with a fracture neck of femur [FNF] need blood transfusion. The incidence of such fractures is steadily increasing ${ }^{(1)}$ but, in spite of much research ${ }^{(2,3,45)}$, there has not emerged a set transfusion protocol, which is accepted and practised by all orthopaedic units.

Conventional practice is that blood must be cross-matched and made available before surgery for all patients with FNF. Most anaesthetists insist on this arrangement before surgery. The other convention is that any patient with a pre-op haemoglobin of less than $10 \mathrm{~g} / \mathrm{d} 1$ must be transfused preoperatively. This rule of thumb is justified on grounds of the safety of the patient (i.e. adequate oxygen carriage) during anaesthesia.

We feel that our current practice leads to the waste of resources, as not all patients will need transfusion after surgery. A unit of red cells costs approximately $£ 37$. The cost of grouping and antibody screening is $£ 15$, and to crossmatch each unit costs a further $£ 5$. Work done out of hours is even more costly. Given the large numbers of patients involved, these figures add up to a considerable total.

We studied retrospectively the blood transfusion requirements of 91 elderly patients (age $>65$ years) with FNF between 1st June 1995 and 31st January 1996. Only patients who underwent hemiarthroplasty and internal fixation with a dynamic hip screw were included. Those who needed percutaneous cannulated screws were excluded, as they do not usually need to be transfused.

The aims of the study were to answer the following questions:

1 What is the average fall in Hb after surgery?

2 At what level of pre-operative $\mathrm{Hb}$ is the patient most likely to need transfusion?

3 Is it absolutely necessary to have blood cross-matched and available before surgery?

\section{METHODS}

Ninety-four elderly patients were identified from our theatre records. Three were excluded, as one had multiple fractures and the other two had pathological fractures from multiple secondaries. Their medical records were studied in detail to assess the pre-op and post-op $\mathrm{Hb}$, the types of surgery required, the grade of surgeon, and the amount and timing of blood transfusion.

\section{RESULTS}

There were 76 females and 15 males of age range 66-102 years (average 84 years). Fifty had dynamic hip screw fixation (DHS) and 41 hemiarthroplasty (24 cemented Bateman's prosthesis and 17 Austin Moore prosthesis).

The patients were divided into five groups (Table 1). Group I did not require transfusion. The other groups were divided depending upon the timing of the transfusions.

Thirty patients $(33 \%)$ did not require blood transfusion. Their pre-op Hb range was 11-14.7g/dl (mean 13.1) and their post-operative levels were $9.2-13.1 \mathrm{~g} / \mathrm{dl}$ (mean $10.9 / \mathrm{dl}$ ). The mean fall in $\mathrm{Hb}$ was $2.2 \mathrm{~g} / \mathrm{dl}$ per patient. There was no correlation with the grade of surgeon operating.

Sixty-one patients $(67 \%)$ were transfused (Table 2$)$. In the pre-operative period (Group II) six patients with a preoperative $\mathrm{Hb}<10 \mathrm{~g} / \mathrm{dl}$ (range 8.4-9.4) needed blood transfusion. During the intra-operative period (Group III) four patients with a pre-operative $\mathrm{Hb}$ within the range 9.8-10.1 g/dl were transfused. Post-operatively eleven patients with pre-operative $\mathrm{Hb}$ in the range 9.8-14.3 (mean 11.1) were transfused in their immediate post-operative period, i.e. within 12 hours (Group IV) and the remainder (40 patients) were transfused at between 24 hours and six days (Group V). $\mathrm{The} \mathrm{Hb}$ levels of these groups are shown in Table 1 .

\begin{tabular}{|l|c|c|c|}
\hline GROUP & NUMBER & $\begin{array}{c}\text { PRE-OP } \\
\text { (mean in brackets) }\end{array}$ & POST-OP \\
\hline I no transfusion & 30 & $11.0-14.7(13.1)$ & $9.2-13.1(10.9)$ \\
\hline II pre-op transfusion & 6 & $8.4-9.4(8.8)$ & $10.7-14.4(12.4)$ \\
\hline III per-op transfusion & 4 & $9.8-10.1(10.0)$ & $9.6-12.3(10.8)$ \\
\hline $\begin{array}{l}\text { IV post-op } \\
\text { transfusion <12 hours }\end{array}$ & 11 & $9.8-14.3(11.1)$ & $9.1-12.7(10.9)$ \\
\hline $\begin{array}{l}\text { V post-op transfusion } \\
\text { days 1-6 }\end{array}$ & 40 & $10.5-15(12.2)$ & $6.4-10(8.5)$ \\
\hline
\end{tabular}

Table 1-Groups/haemoglobin levels

The timing of the transfusion in relation to the operation and the number of units transfused are shown in Table 2. Altogether 137 units of blood were transfused ( 2.35 units per transfused patient). Of the six patients who were transfused before surgery, three needed additional transfusion during their period of recovery. Two patients who were transfused on the day after surgery needed further blood later (day $5 \&$ day 7).

A further search was made to identify the group which was most likely to need transfusion in the post-operative period. 
Patients with an admission $\mathrm{Hb}$ less than $12 \mathrm{~g} / \mathrm{dl}$ were looked at. There were thirty-three patients with a pre-operative $\mathrm{Hb}$ range from 9.8 to $12 \mathrm{~g} / \mathrm{dl}$. These patients were not transfused pre-operatively. Of this group $28(85 \%)$ were subsequently transfused.

Of the 50 patients who underwent internal fixation with a DHS, $37(74 \%)$ needed blood transfusion. Thirteen patients $(54 \%)$ in the cemented hemiarthroplasty group and 11 patients $(65 \%)$ in the uncemented group needed transfusion. Using the Chi Squared test, no significant difference in transfusion rates was found between the two major groups of internal fixation with DHS and hemiarthroplasty $(\mathrm{p}=0.18)$.

\section{DISCUSSION}

The average drop in haemoglobin was $2.2 \mathrm{~g} / \mathrm{dl}$ in the nontransfused group. In a recent study from Redditch ${ }^{(6)}$ the average drop in a comparable group was found to be $1.57 \mathrm{~g} / \mathrm{dl}$.

McBride and Stother ${ }^{(2)}$ found that only ten out of 113 patients $(7 \%)$ with a pre-op haemoglobin of $>10 \mathrm{~g} / \mathrm{dl}$ required intra-operative transfusion. Our current practice is to transfuse most patients who have an admission level less than $10 \mathrm{~g} / \mathrm{dl}$. Therefore, very few need to be transfused during surgery, only four $(6.6 \%)$ in our current study.

Robbins and Steingold ${ }^{(3)}$ reported that in patients with an admission haemoglobin of $>11 \mathrm{~g} / \mathrm{dl}$, only $17 \%$ of the cases of hemiarthroplasty and $11 \%$ needing blade and plate fixation required transfusion. Our study shows that only $15 \%$ of the patients with an admission haemoglobin of $>12 \mathrm{~g} / \mathrm{dl}$ need to be transfused.

Kurdy and $\operatorname{Hokkan}^{(4)}$ found that patients with intertrochanteric fractures (the extracapsular type), with a haemoglobin level of $10-12 \mathrm{~g} / \mathrm{dl}$ should have cross-matched blood. All other patients with a haemoglobin of $>10 \mathrm{~g} / \mathrm{dl}$ could safely have blood grouped and screened. The data from Peterborough $^{(5)}$ also support the view that it is rare for patients with an admission haemoglobin of $>11 \mathrm{~g} / \mathrm{dl}$ to require perioperative blood transfusion. It should therefore be safe to operate on these patients without blood being cross-matched, so long as the blood transfusion laboratory has grouped and saved a sample of serum. Muir ${ }^{(7)}$ formulated a transfusion protocol that all patients with a pre-operative haemoglobin of $>11 \mathrm{~g} / \mathrm{dl}$ should have group and antibody screen only before surgery.

We recommend that cross-matching should be requested only for those with an admission haemoglobin of $<12 \mathrm{~g} / \mathrm{dl}$. For the rest, group and save is all that is required.

Most requests for transfusion in this context are made outof-hours ${ }^{(6)}$. Considering that 30 patients did not need transfusion and a further 40 patients needed it well after surgery, it is clearly a waste of resources to request a crossmatch when transfusion may well be inappropriate or unnecessary in the pre- or per-operative periods.
After surgery, haemoglobin levels must be checked the very next day. This gives both sufficient time for correction of dehydration (so that a true level of haemoglobin can be estimated) and also enables arrangements for transfusion to be made, if necessary at the earliest possible time after surgery.

Thirty patients were transfused between day two and six days after the operation. One could anticipate that in some patients rehabilitation may have been delayed until the patients were transfused. This delay would also lead to increased length of stay in the hospital.

One must not overlook that these elderly patients would need to be assessed individually. Some of them would have low cardiac reserves. In a normal healthy adult a postoperative haemoglobin of up to $7 \mathrm{~g} / \mathrm{dl}$ may be acceptable ${ }^{(8.9)}$. For elderly patients, however, setting a lower acceptable limit is not possible. In older and fragile patients a combination of severe acute anaemia with coronary stenosis may result in myocardial ischaemia ${ }^{(10)}$. Each patient, therefore, will need an adequate clinical assessment to judge the requirement for blood transfusion.

\begin{tabular}{|l|c|c|}
\hline $\begin{array}{l}\text { TRANSFUSION } \\
\text { GROUP }\end{array}$ & $\begin{array}{c}\text { NO. OF } \\
\text { PATIENTS }\end{array}$ & $\begin{array}{c}\text { TOTAL UNITS } \\
\text { TRANSFUSED }\end{array}$ \\
\hline II (pre-op) & 6 & 17 \\
\hline III (per-op) & 4 & 10 \\
\hline IV (post-op <12 hours) & 11 & 20 \\
\hline G day 1 after surgery & 10 & 20 \\
\hline R day 2 & 13 & 24 \\
\hline O day 3 & 10 & 28 \\
\hline U day 4 & 3 & 7 \\
\hline P day 5 & 3 & 6 \\
\hline V day 6 & 1 & 3 \\
\hline
\end{tabular}

Table 2 - Transfusion requirements

It has also been advocated by a recent study that by administering oral iron supplements to such patients, the eventual need for transfusion can be further reduced ${ }^{(6)}$. In patients with a haemoglobin concentration below $10 \mathrm{~g} / \mathrm{dl}$, oral iron therapy will initially provide 40 to $60 \mathrm{mg}$ iron per day for erythropoiesis, permitting red cell production to increase to two to four times normal and haemoglobin concentration to rise by about $0.2 \mathrm{~g} / \mathrm{dl} / \mathrm{day}{ }^{(11)}$. Oral iron supplement on average raises the $\mathrm{Hb}$ level by $1 \mathrm{gm}$ per week. A prospective randomised study in patients with FNF to evaluate this is currently being run at our orthopaedic unit.

In spite of the published literature, very few hospitals have a set protocol. Junior doctors tend to cross-match too much blood. Requests are made out-of-hours. In any health service care system, any practice which leads to waste of resources is to be deprecated. On the basis of our study and the current research, we present the following protocol. This has been prepared with the approval of the orthopaedic, haematology and anaesthetic teams. 


\section{GUIDELINES FOR BLOOD TRANSFUSION REQUIREMENTS FOR ELDERLY PATIENTS WITH FRACTURED NECK OF FEMUR}

\section{A AT TIME OF ADMISSION}

1 Group and save for all patients. Request cross-match for only those patients with a pre-op $\mathrm{Hb}$ of $<12 \mathrm{~g} / \mathrm{dl}$.

2 If the admission is out-of-hours, then any Blood Bank request for cross-match is to be made during the next day shift. Those patients who are significantly anaemic $(\mathrm{Hb}$ $<8 \mathrm{~g} / \mathrm{dl}$ ) on admission and those who are going to be operated upon immediately following admission need cross-matching.

3 Patients with a pre-op $\mathrm{Hb}$ of $8-10 \mathrm{~g} / \mathrm{dl}$ may need transfusion peri-operatively. Please discuss with the consultant anaesthetist (Trauma List or ICU Consultant).

4 Patients do not need to be transfused overnight, unless there is cardiovascular compromise, but adequate hydration and electrolyte balance is essential.

\section{B AFTER SURGERY}

1 Check $\mathrm{Hb}$ the day following surgery. Remember that cross-matched blood is held for 48 hours only before being reallocated and blood transfusion should proceed within 48 hours of the request.

2 If $\mathrm{Hb}<9 \mathrm{~g} / \mathrm{dl}$, then transfuse two or three units of red cells depending on the level.

3 If $\mathrm{Hb}$ between 9 and $10 \mathrm{~g} / \mathrm{dl}$, administer Ferrocontin 1 tablet daily (total period -6 weeks), unless the clinical condition demands a blood transfusion.

4 If $\mathrm{Hb} \geq 10 \mathrm{~g} / \mathrm{dl}$ then blood transfusion is not required in most cases. Some cases may need iron supplements.

At all times please ensure adequate hydration.

Aim to achieve pre-discharge $\mathrm{Hb} \geq 10 \mathrm{~g} / \mathrm{dl}$.

\section{AVOID unnecessary $x$-match \\ unnecessary out-of-hours requests requesting blood $>\mathbf{4 8}$ hours after $x$-match unnecessary transfusion when iron will suffice}

Summary box

\section{REFERENCES}

1 Bulstrode C. Keeping up with orthopaedic epidemics. $\mathrm{Br}$ Med J 1987; 295:514

2 McBride D J, Stother I G. Blood transfusion requirements in elderly patients with surgical treated fractures of the femoral neck. J Roy Coll Surg 1988; 33:311-313

3 Robbins J, Steingold R F. Blood use in urgent operations for patients with fracture of the femoral neck. Injury 1986; 17:265-266

4 Kurdy N M G, Hokan R. A. cross matching policy for fractures of the proximal third of the femur. Injury 1993; 24:521-524

5 Parker M J. A cross-matching policy for fracture of the proximal third of the femur; blood transfusion and injured patients. Injury 1994; 25:486-487

6 Obeid D, Davis C, Awaad M. An audit of blood usage in patients with fractured neck of femur. Bull Roy Coll Pathol 1996; $94: 16-18$

7 Muir L. Blood transfusion requirement in femoral neck fractures. Ann R Coll Surg Engl 1995; 77:453-456

8 Mollinson P L, Englefriet C P, Contreras M. Blood Transfusion in Clinical Medicine. 9th Ed. Blackwell Scientific Publications. 1994

9 McClelland B. Handbook of Transfusion Medicine. HMSO Publications Centre, 2nd ed. 1996, Chap 4; 49

10 Most A S, Ruocco N A, Gewirtz H. Effect of a reduction in blood viscosity on maximal oxygen delivery distal to a moderate coronary stenosis. Circulation 1986; 74:1085-1092

11 Hillman R S, Henderson P A. Control of marrow production by relative iron supply. J Clin Inves 1969; 48:454 